\title{
Synergistic inhibition of colon cancer cell growth by a combination of atorvastatin and phloretin
}

\author{
MO ZHOU*, JINKAI ZHENG ${ }^{*}$, JINFENG BI, XINYE WU, JIAN LYU and KUN GAO \\ Institute of Food Science and Technology, CAAS, Key Laboratory of Agro-Products Processing, \\ Ministry of Agriculture, Beijing 100193, P.R. China
}

Received May 21, 2017; Accepted November 20, 2017

DOI: $10.3892 / \mathrm{ol} .2017 .7480$

\begin{abstract}
Atorvastatin (ATST), a drug commonly used to reduce the levels of cholesterol and low-density lipoproteins, is a prospective agent for the prevention of colorectal cancer in patients with hyperlipidemia. ATST in combination with functional components is a promising strategy for cancer chemoprevention. In the present study, the growth inhibitory effect of ATST combined with phloretin (PT) on SW620 and HCT116 colon cancer cells was investigated. The results of MTT assays indicated that the combination of PT and ATST markedly reduced cell survival in both cell lines compared with PT or ATST treatment administered individually. The interaction indexes between PT and ATST, which were used to analyze their interaction pattern, were computed by the median-effect equation. The interaction indexes of each PT and ATST concentration pair were $<1.0$, which indicated a strong synergistic effect between the two compounds. The data obtained by flow cytometry and western blot analysis of cleaved-poly (ADP-ribose) polymerase indicated a synergistic effect resulted in apoptosis and cell cycle arrest at the $\mathrm{G}_{2} / \mathrm{M}$ checkpoint. Furthermore, combined treatment with PT and ATST markedly downregulated the expression of cyclin B and upregulated the expression of phospho-cdc2 and Myt1, which suggested that the activation of cdc 2 was downregulated. This combined treatment strategy enhanced the anti-cancer activity of ATST at a relatively low dosage and suggested a possible method of preventing colorectal cancer in patients with hyperlipidemia.
\end{abstract}

Correspondence to: Professor Jinfeng $\mathrm{Bi}$, Institute of Food Science and Technology, CAAS, Key Laboratory of Agro-Products Processing, Ministry of Agriculture, 2 Yuanmingyuan West Road, Beijing 100193, P.R. China

E-mail: bjfcaas@126.com

*Contributed equally

Key words: atorvastatin, phloretin, synergy, colon cancer cells, anti-proliferation, cell cycle, cdc2 activation

\section{Introduction}

Colorectal cancer is one of the most common malignancies worldwide; imbalanced dietary patterns, such as the large consumption of red and processed meat, have been identified as a contributor to the increasing incidence of colorectal cancer $(1,2)$. This dietary habit causes increased levels of cholesterol and low-density lipoproteins (LDL) in the blood, which can eventually develop into hyperlipidemia. According to recent data, hyperlipidemia is one factor contributing to the increased incidence of colorectal cancer $(3,4)$ as high levels of cholesterol and LDL can enhance cancer growth and metastasis $(5,6)$. Statin compounds are the most commonly used drugs to reduce the levels of cholesterol and LDL; therefore, using statins to prevent cancer is a recommended treatment for patients with hyperlipidemia. Nielsen, Nordestgaard and Bojesen (7) have reported that the use of statins may decrease cancer mortality in Danish population. Moreover, numerous clinical studies revealed an association between statin consumption and cancer risk; however, the data regarding colorectal cancer were inconsistent $(8,9)$. Consequently, it is worth evaluating the anti-cancer effect of statins for the purpose of applying them in colorectal cancer prevention. Atorvastatin (ATST) is one of the main statins in clinical circulation. Prior studies have indicated the synergistic antitumor effects of ATST when combined with non-steroidal anti-inflammatory drugs $(10,11), \gamma$-tocotrienol (12) or green tea polyphenols (13). Therefore, exploring a combinational strategy between statins and other dietary components may be an effective way to prevent colorectal cancer in patients with hyperlipidemia.

Previous studies revealed that apples may reduce the risk of cancer, and that polyphenol and flavonoid compounds can also contribute to this chemopreventive effect (14-17). Phloretin (PT) is one of the most abundant phenolic phytochemicals in apples and apple products. Numerous studies have reported on the antitumor activities of PT, including its ability to suppress cell growth and induce apoptosis in human hepatoma cells, HL-60 human leukemia cells, B16 mouse 4A5 melanoma cells and HT29 human colon cancer cells (18-21). Both in vitro and in vivo studies have revealed that PT could potentiate the antitumor effects of paclitaxel via the induction of cell apoptosis (22). Another study showed that cytochalasin B could enhance the PT-induced apoptosis of HepG2 cells (21). 
Although, according to these reports, the combination of PT with other compounds may enhance its antitumor effect, little evidence is currently available to support a synergistic effect between PT and statins.

In this study, the potential synergistic inhibitory effect between PT and ATST was evaluated in human colon cancer cells. The synergistic mechanisms involving the cell cycle and apoptosis were also investigated. The results of the present study have provided a potential novel chemoprevention strategy for the hyperlipidemia population, specifically via the combination of dietary functional components and statin compounds.

\section{Materials and methods}

Cell lines and reagents. The human colon cancer cells SW620 and HCT116 were purchased from the Institute of Basic Medical Cell Center, Chinese Academy of Medical Sciences. ATST and PT were purchased from the National Institutes for Food and Drug Control (Beijing, China). MTT, propidium iodine (PI) and RNase were purchased from Sigma-Aldrich (Merck KGaA, Darmstadt, Germany). The Annexin V conjugate was purchased from Invitrogen (Thermo Fisher Scientific, Inc., Waltham, MA, USA). Lysis buffer and a BCA assay kit were purchased from Beyotime Co., (Haimen, China). Antibodies for poly-ADP-ribose polymerase (PARP), cleaved-PARP, caspase-3, cyclin B1, phospho-cdc2 (Tyr15) and Myt1 were purchased from Cell Signaling Technology, Inc., (Danvers, MA, USA).

Cell viability assay. Human SW620 and HCT116 colon cancer cells were seeded into 96-well plates (2,000 cells/well). After $24 \mathrm{~h}$, the cells in each well were treated with a series of concentrations of PT, ATST or a combination (ratio of 10:1, PT and ATST, respectively). After 24 and $48 \mathrm{~h}$, cell viability was determined using an MTT assay.

Analysis of synergy. The synergy analysis was conducted according to the median-effect equation (23). It was assumed that the dose-response model follows the median-effect equation, $f_{a} / f_{u}=\left(D / D_{m}\right) m$; the dose-effect curve, $\log \left(f_{a} / f_{u}\right)=m \log D-m \log D_{m}$, is the $\log$ arithmic form of the median-effect equation, which is a linear regression model with the independent variable $\log D$ and the dependent variable $\log \left(f_{a} / f_{u}\right)$. $D$ is the dose; $D_{m}$ is the dose required for a $50 \%$ effect $\left(\mathrm{IC}_{50}\right) ; f_{a}$ is the fraction affected by $D$, which is the same as the ratio of surviving cells; $f_{u}$ is the unaffected fraction, which is the same as the ratio of non-surviving cells, $m$ is the slope. This equation is applied for calculating the effective doses of agent 1 and agent 2, and of a fixed ratio of combination agents, using data from an MTT assay. Suppose that the combination $\left(D_{1}, D_{2}\right)$ exert the same effect $x$ as agent 1 alone at dose level $D_{x l}$, and agent 2 alone at dose $D_{x 2} . D_{x 1}$ and $D_{x 2}$, were calculated from the dose-effect curve. The interaction index $\left.=D_{1} / D_{x 1}+D_{2} / D_{x 2}+\alpha+I_{1} \cdot{ }_{2}\right) /\left(D_{x 1} \cdot 1_{x 2}\right)$, If the agents are mutually exclusive, $\alpha=0$; if the agents are mutually nonexclusive, $\alpha=1$. The interaction index was used to determine whether the combinational dose $\left(D_{1}, D_{2}\right)$ was additive, synergistic or antagonistic, depending on an interaction index of $1,<1$ or $>1$, respectively.
Measurement of cell apoptosis. Cell apoptosis was assessed using flow cytometry combined with an Annexin V/PI double-staining assay. After being treated with PT $(100 \mu \mathrm{M})$, ATST $(10 \mu \mathrm{M})$ or a combination of the two $(100 \mu \mathrm{M}+10 \mu \mathrm{M}$, respectively) for $48 \mathrm{~h}$, cells were harvested, washed with ice-cold PBS and resuspended in $100 \mu \mathrm{l}$ Annexin-binding buffer (10 mM HEPES, $140 \mathrm{mM} \mathrm{NaCl}$, and $2.5 \mathrm{mM} \mathrm{CaCl}_{2}$, $\mathrm{pH}$ 7.4), which contained $5 \mu \mathrm{l}$ Annexin $\mathrm{V}$ conjugate and $0.1 \mu \mathrm{g}$ PI. After incubation at room temperature for $15 \mathrm{~min}$, the cell suspension was gently mixed with $400 \mu$ l Annexin-binding buffer and analyzed by FACSCalibur flow cytometry (BD Biosciences, Franklin Lakes, NJ, USA) at $488 \mathrm{~nm}$.

Detection of the cell cycle. Flow cytometry was performed to analyze the cell cycle distribution. After being treated with PT $(100 \mu \mathrm{M})$, ATST $(10 \mu \mathrm{M})$ or a combination of the two $(100 \mu \mathrm{M}+10 \mu \mathrm{M}$, respectively) for $48 \mathrm{~h}$, cells were harvested and washed with ice-cold PBS, then resuspended in $70 \%$ ethanol and stored at $4^{\circ} \mathrm{C}$ for $24 \mathrm{~h}$. After $24 \mathrm{~h}$, cells were pelleted by centrifugation, incubated with RNase $(50 \mu \mathrm{M} / \mathrm{ml}$ in PBS) and stained with PI (1 mg/ml in PBS) in the dark at $37^{\circ} \mathrm{C}$ for $30 \mathrm{~min}$. Cells were then evaluated at a wavelength of $550 \mathrm{~nm}$ using a FACSCalibur flow cytometer (BD Biosciences), and the data were analyzed with Summit v5.0 software.

Western blot analysis. After being exposed to PT $(100 \mu \mathrm{M})$, ATST $(10 \mu \mathrm{M})$ or a combination of the two $(100 \mu \mathrm{M}+10 \mu \mathrm{M}$, respectively) for $48 \mathrm{~h}$, the cells were harvested into tubes. The cell pellet from each tube was incubated on ice for $30 \mathrm{~min}$ with $300 \mu 1$ lysis buffer containing phenylmethanesulfonyl fluoride (PMSF, $1 \mathrm{mM}$ ) and cocktails (1:10). The cell pellets were resuspended and centrifuged at 12,000 rpm for $20 \mathrm{~min}$ to collect the supernatants. Proteins were subjected to quantification using a BCA assay kit and then resolved via SDS-PAGE. After electrophoresis, the proteins were transferred to a polyvinylidene fluoride membrane, which was then blocked. The membranes were incubated with different primary antibodies at the concentrations recommended by the manufacturer at $4^{\circ} \mathrm{C}$ overnight. Subsequently, the membranes were incubated with secondary antibodies at room temperature for $1 \mathrm{~h}$, prior to visualization using an enhanced chemiluminescence reagent. Antibodies for PARP, cleaved-PARP, caspase-3, cyclin B1, Tyr15 and Myt1 were purchased from Cell Signaling Technologies, Inc.

Statistical analysis. All data were obtained from at least three independent experiments and are presented as the mean \pm standard deviation. A Student's t-test was used to assess differences between two groups. One-way analysis of variance and the Dunnett's post hoc test were used to compare differences among multiple groups. $\mathrm{P}<0.05$ was considered to indicate a statistically significant difference.

\section{Results}

A synergistic anti-proliferative effect was observed in SW620 and HCT116 cells treated with a combination of PT and ATST. The growth inhibitory effect of PT, ATST and their combination was evaluated in SW620 and HCT116 cells at 24 and $48 \mathrm{~h}$. The tested concentrations of PT were 50, 75, $100,125,150$ and $200 \mu \mathrm{M}$; the tested concentrations of ATST 
A
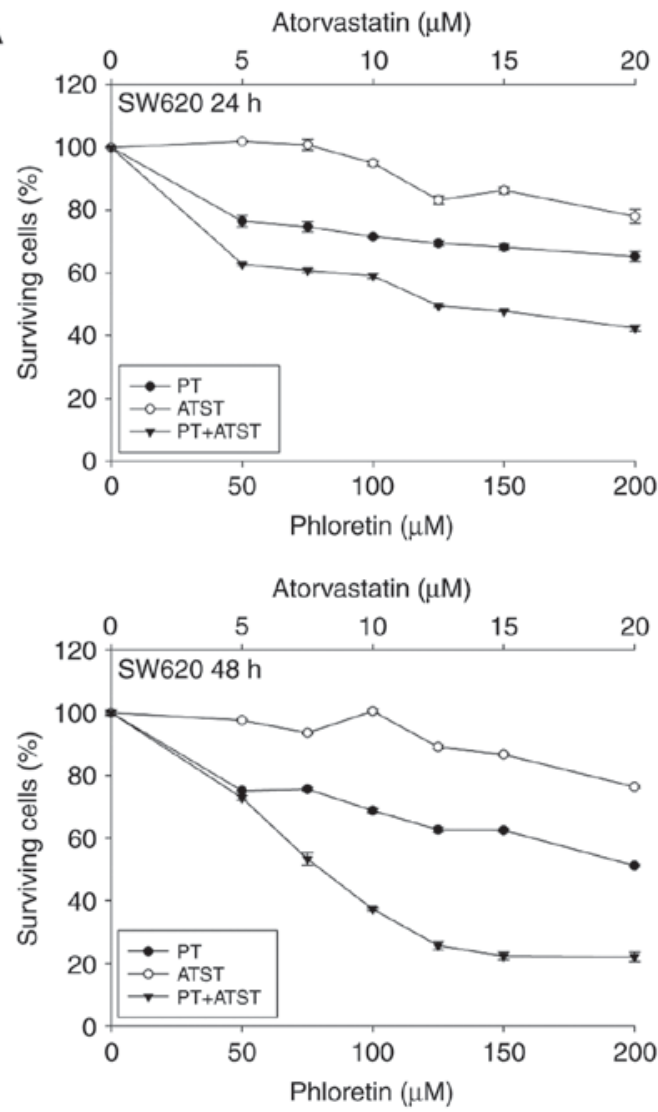
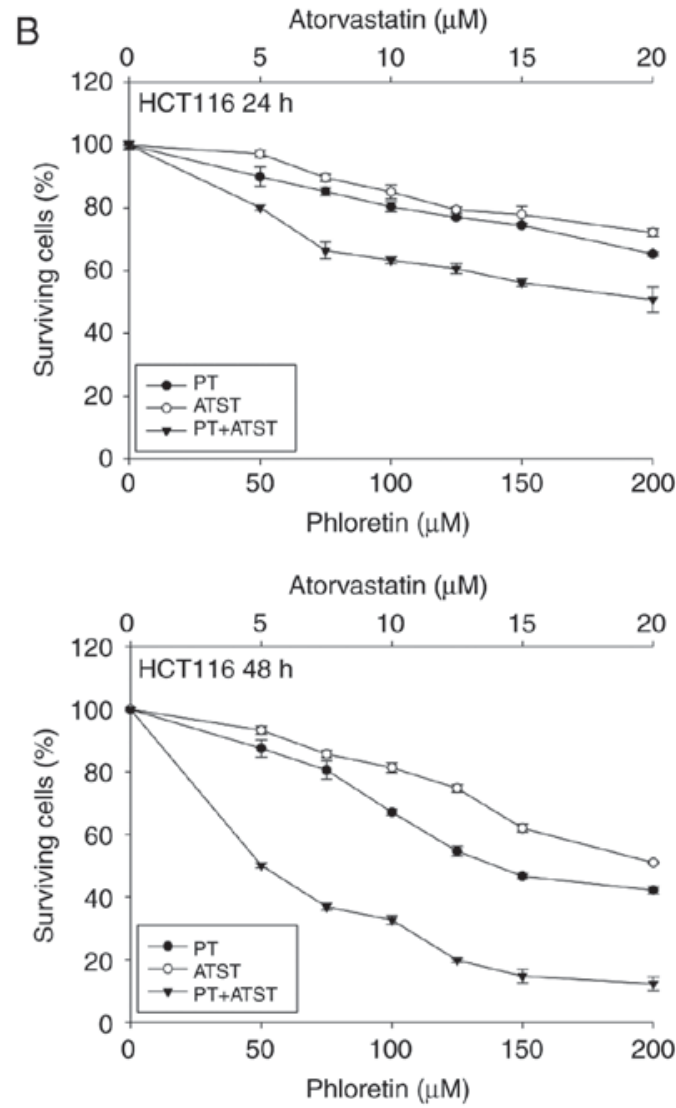

Figure 1. The viability of SW620 (A) and HCT116 cells (B) after treatment with PT, ATST and their combinations. Cells were treated with a series of dosages of PT $(0,50,100,150$ and $200 \mu \mathrm{M})$, ATST $(0,5,10,15$ and $20 \mu \mathrm{M})$, or a combination at a fixed ratio of $10: 1$ for 24 and 48 h, and then cell viability was measured using an MTT assay. Data are shown as the mean \pm SD $(n=5)$, and the surviving cell percentage of the respective controls were set as $100 \%$.

were $5,7.5,10,12.5,15$ and $20 \mu \mathrm{M}$; the combination ratio of PT to ATST was 10:1. After exposure to these treatments for 24 and $48 \mathrm{~h}$, cell survival was measured using an MTT assay. The results (Fig. 1) showed that PT and ATST exhibited time- and dose-dependent growth inhibitory effects on the two cell lines. The $\mathrm{IC}_{50}$ values for single PT and ATST treatments in HCT116 cells were 137.48 \pm 2.14 and $19.52 \pm 1.29 \mu \mathrm{M}$, respectively. However, for SW620 cells, the $\mathrm{IC}_{50}$ value of PT was $191.70 \pm 2.28 \mu \mathrm{M}$, and ATST did not show a significant inhibitory effect on cell growth.

Compared with individual PT and ATST treatments, the combination markedly decreased cell viability. The cell viability rates at $24 \mathrm{~h}$ and $48 \mathrm{~h}$ following treatment with PT $(100 \mu \mathrm{M})$ combined with ATST $(10 \mu \mathrm{M})$ were $59.08 \pm 0.73 \%$ and $37.27 \pm 0.39 \%$, respectively, for SW620 cells, and $63.35 \pm 1.08 \%$ and $32.65 \pm 1.34 \%$ for HCT116 cells, respectively. Furthermore, to determine whether the enhanced inhibitory effect observed with combined PT/ATST was additive or synergistic, the combination indexes were computed using the aforementioned Chou and Talalayla method.

The median-effect plots of these two cells are shown in Fig. 2A and B, and indicate that the linear regression model fit better with the dose-dependent manner of PT, ATST and their combinations. According to the median-effect equation, the effect doses of PT, ATST and their combination at a dosage ratio of 10:1 were computed, and then used to compute the interaction indexes. As presented in Fig. $2 \mathrm{C}$ and D, the interaction indexes of each PT and ATST concentration pair were $<1.0$; notably, a proportion was $<0.5$. Consequently, it was determined the combination of PT and ATST generated a strong synergistic inhibitory effect on SW620 and HCT116 cell growth. As the results showed that the inhibitory effect of combination treatment at $48 \mathrm{~h}$ were significantly stronger than the ones at $24 \mathrm{~h}$, we therefore selected the time point of $48 \mathrm{~h}$ to carry out the following experiments.

Combined PT and ATST treatment induces apoptosis. The results revealed a strong synergistic anti-proliferative effect exerted by the combined PT and ATST treatment of SW620 and HCT116 cells. This observation prompted us to determine whether the decreased cell survival was related to apoptosis. An Annexin V/PI double staining assay was used to determine the proportion of apoptotic cells. The results are presented in Fig. 3A and B. In both SW620 and HCT116 cells, the percentage of apoptotic cells in the group treated with combined PT and ATST was significantly higher than for those cells treated with each agent alone. Furthermore, the expression levels of PARP and cleaved-PARP were determined (Fig. 3C). The PARP fragments were significant in SW620 and HCT116 cells following the combination treatments. By contrast, there were no significant levels of cleaved-PARP detected in either cell line following treatment with the single agents. These observations, together with the results of the MTT assay, indicated that combined treatment with PT and ATST could induce colon cancer cell apoptosis.

Combined PT and ATST treatment causes cell cycle arrest at the $\mathrm{S}$ phase. The results warranted us to hypothesize that the 

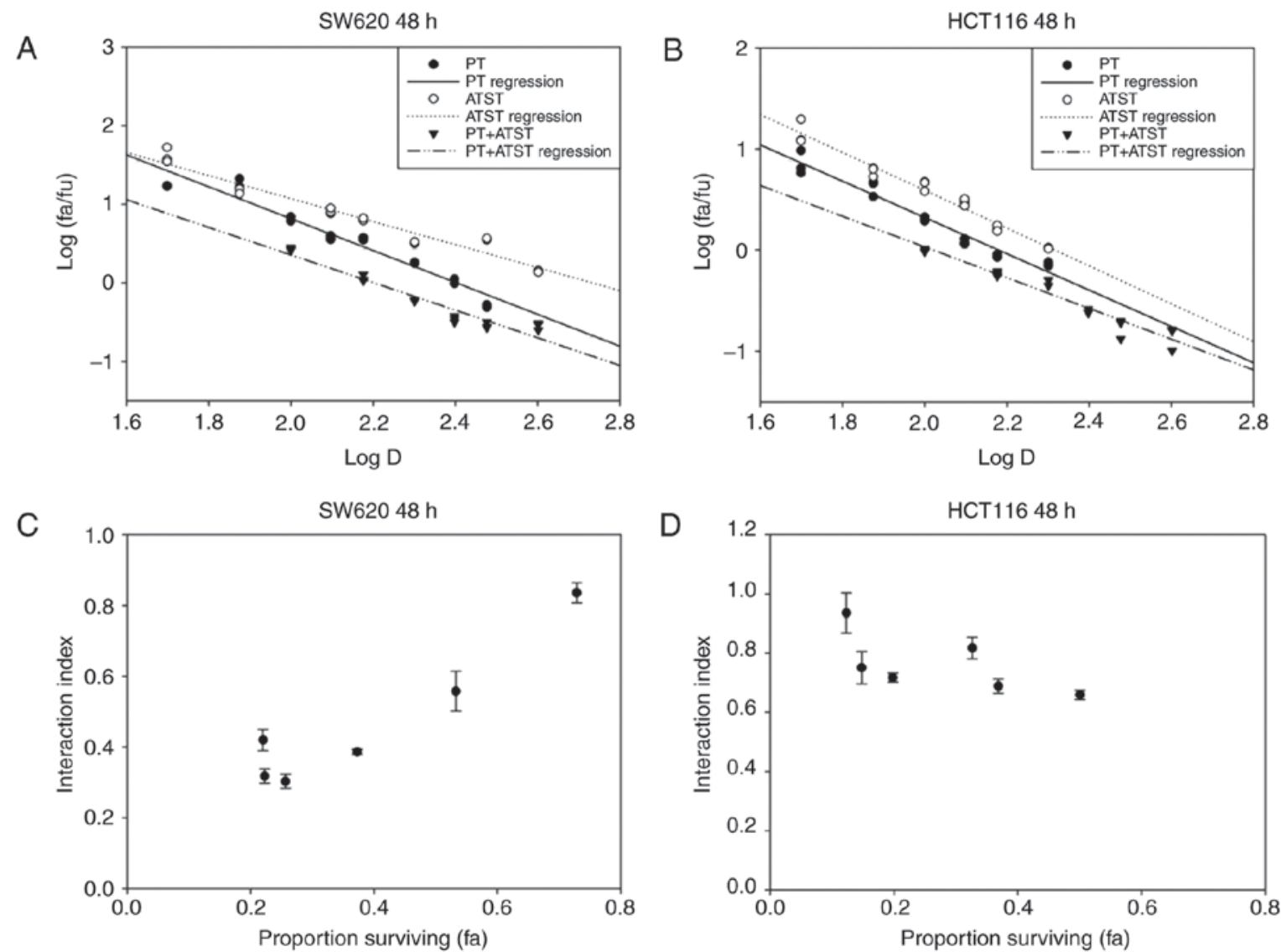

Figure 2. Median-effect and interaction index plots of PT, ATST or a combination in SW620 (A and C) and HCT116 (B and D) cells. Cells were treated with a series of dosages of PT $(0,50,100,150$ and $200 \mu \mathrm{M})$, ATST $(0,5,10,15$ and $20 \mu \mathrm{M})$ or a combination at a fixed ratio of 10:1 for $48 \mathrm{~h}$, and then cell viability was measured using an MTT assay. Median-effect plots (A, B) and interaction index plots (C and D) were computed with the median-effect equation. Synergy was defined as an interaction index $<1.0$. The data of interaction plots are shown as the mean $\pm \operatorname{SD}(n=5)$.

synergistic effect of PT and ATST on apoptosis may involve cell cycle arrest. Flow cytometry was performed to analyze the cell cycle distribution for both SW620 and HCT116 cells following treatment with PT, ATST or a combination for $48 \mathrm{~h}$. The results (Fig. 4) indicated that individual PT or ATST treatment did not significantly change the cell cycle distribution for the two cell lines. By contrast, combined PT and ATST could alter the distribution of cell cycle. For SW620 cells, a significant increase in the $\mathrm{S}$ phase cell proportion was observed following combined treatment with PT and ATST, which was correspondingly accompanied by a decrease in the $\mathrm{G}_{2} / \mathrm{M}$ phase cell proportion. For HCT116 cells, an increase in the S phase proportion was also observed with combined treatment; however, this increase was slighter when compared with the SW620 cells, and no decrease in the $\mathrm{G}_{2} / \mathrm{M}$ phase proportion was noted. Therefore, the results indicated that combined PT and ATST treatment could arrest SW620 and HCT116 cells in the $\mathrm{S}$ phase.

Combined PT and ATST treatment inhibits cdc2 activation. To further explore the mechanisms underlying the cell cycle arrest, the activity of proteins that perform an important role during progression at the $S$ phase and the $\mathrm{G}_{2} / \mathrm{M}$ checkpoint were examined (Fig. 5). In both SW620 and HCT116 cells, the expression of cyclin B1 was not significantly different between the control and PT-treated groups; for ATST-treated cells, the expression of cyclin B1 was decreased by $\sim 50 \%$. By contrast, combined treatments of PT and ATST markedly suppressed the cyclin B expression in all cells (Fig. 5A). The phosphorylation of cdc2 at Tyr15 was also analyzed, as dephosphorylation at this locus results in the activation of cdc2. The results showed that the activity of p-cdc2 were markedly upregulated following combined treatments (Fig. 5B). Consistently, the activity of Myt1, which is responsible for the phosphorylation of cdc2 at Tyr15, showed a similar pattern (Fig. 5C). These results indicated that PT and ATST synergistically inhibit the activation of cdc2 in both SW620 and HCT116 colon cancer cells.

\section{Discussion}

Since increased 3-hydroxy-3-methylglutaryl coenzyme A (HMG-CoA) levels have been observed in colon cell lines, previous studies have evaluated the anti-cancer activity of statins. Statins are competitive small-molecule inhibitors of HMG-CoA reductase, and could prevent the transformation of HMG-CoA to mevalonate (24). Although in vitro data have suggested that ATST could suppress HCT116 cell growth and induce apoptosis, the effective doses of ATST in these experiments were relatively higher $(50$ and $100 \mu \mathrm{M}$, respectively) $(12,25)$. In our experimental design, the maximum dose of ATST was only $25 \mu \mathrm{M}$. As expected, the results showed that ATST exhibited little effect on HCT116 cell growth and 
A
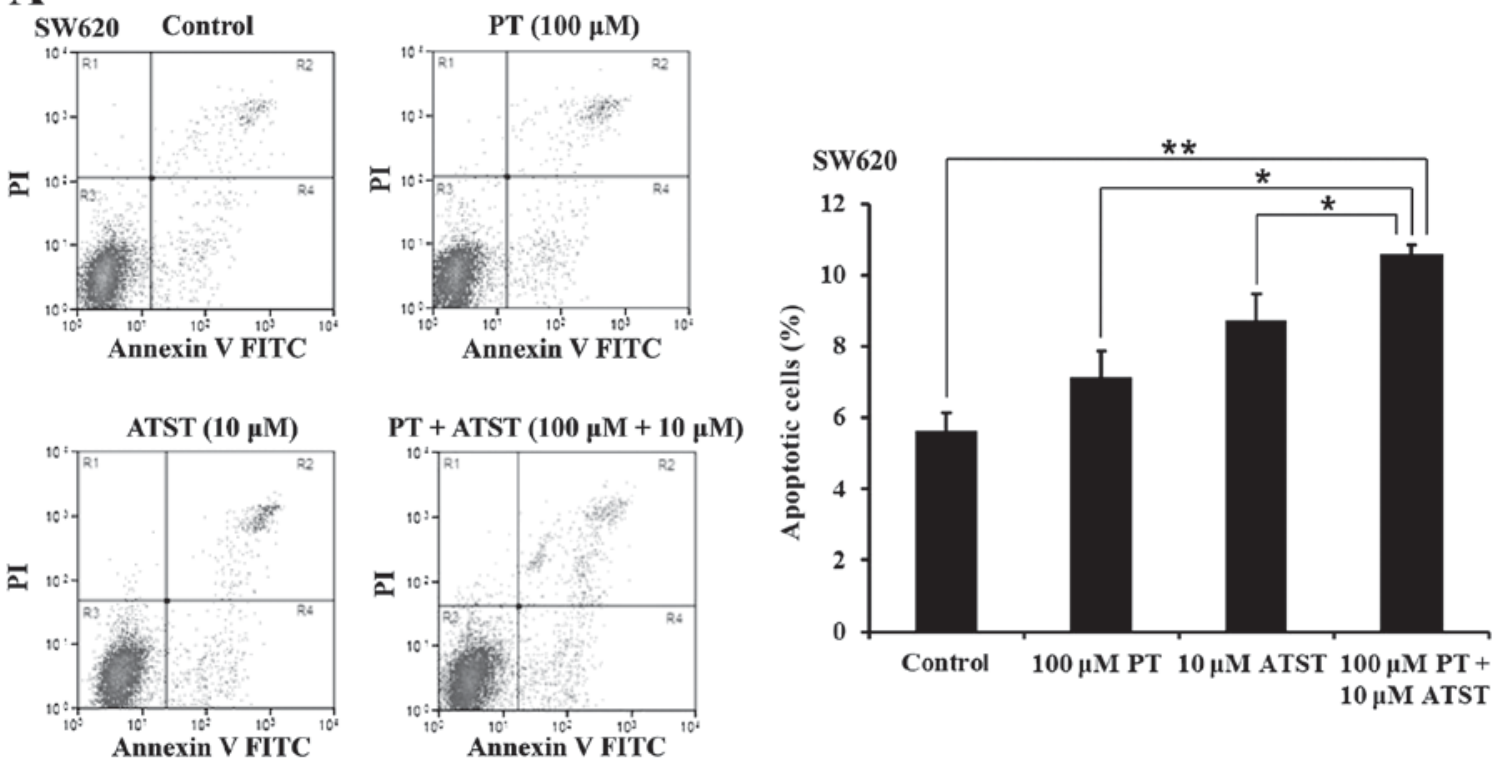

B
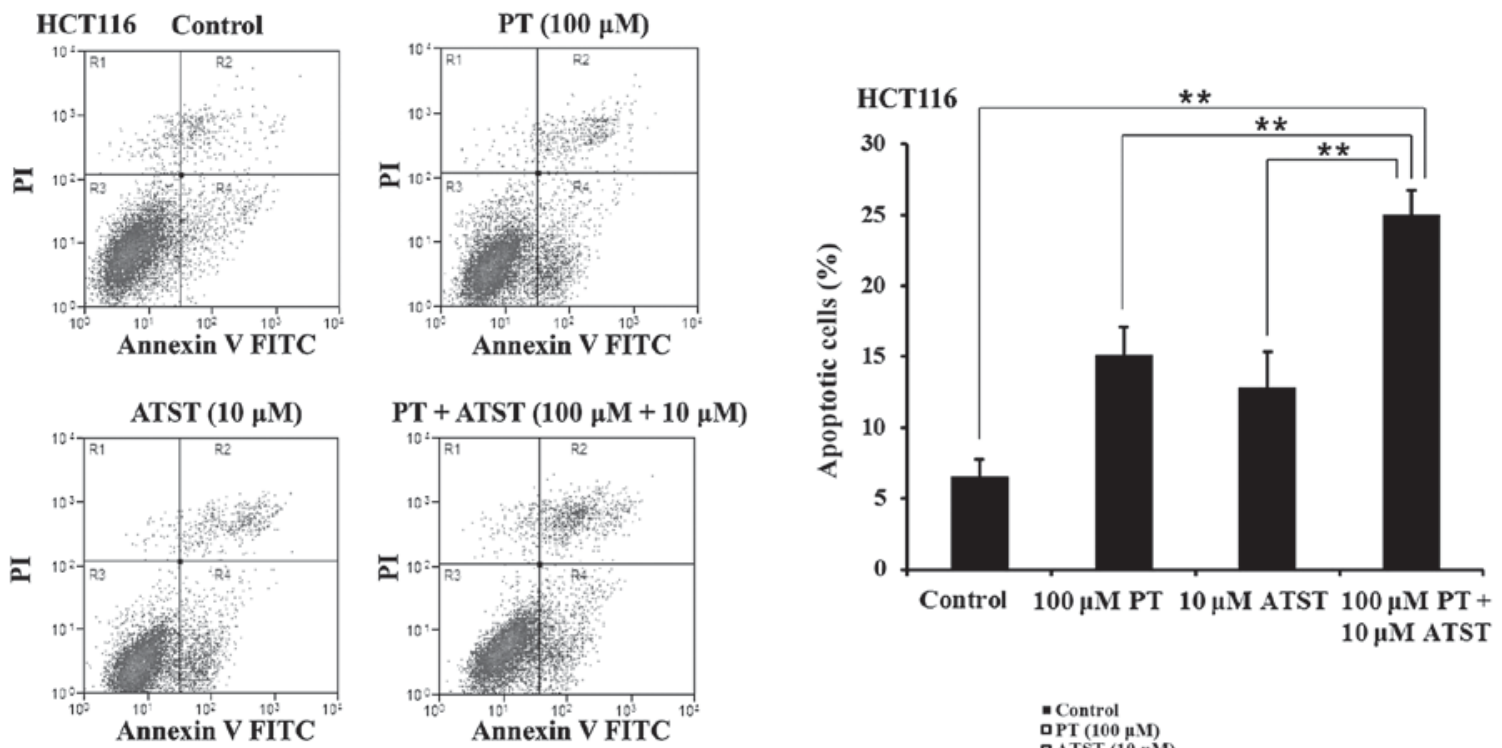

$\mathbf{C}$
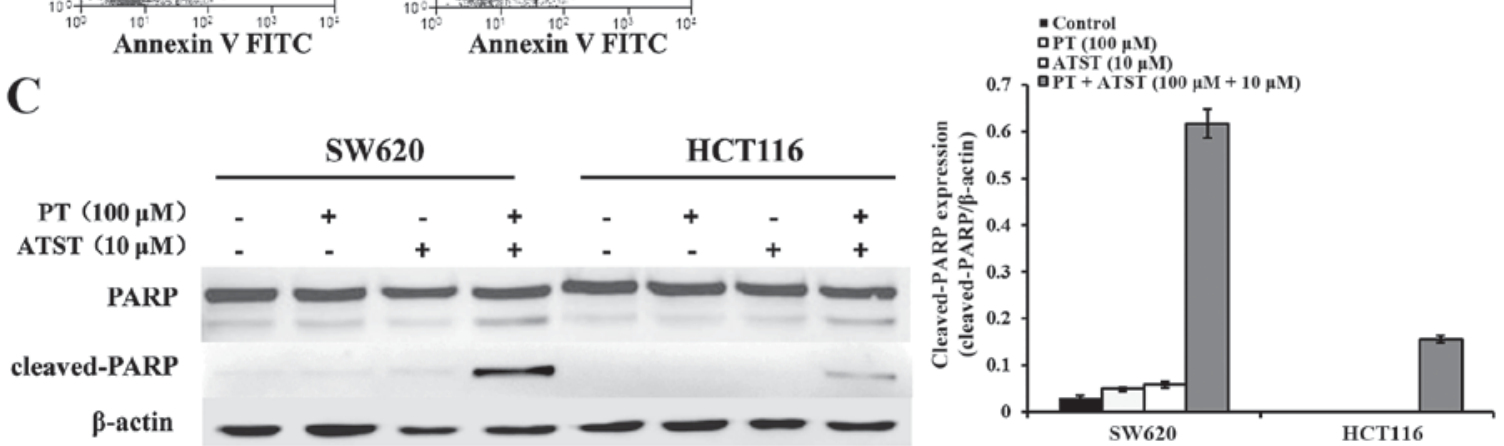

Figure 3. Effects of PT, ATST or a combination on apoptosis (A, SW620; B, HCT116) and cleaved-PARP levels (C). Cells were treated with PT (100 $\mu$ M) ATST $(10 \mu \mathrm{M})$ or a combination of the two for $48 \mathrm{~h}$. Apoptosis was detected by flow cytometry after Annexin V/PI co-staining, and protein levels were analyzed by western blotting. Data are shown as the mean $\pm \mathrm{SD}(n=3)$. ${ }^{*} \mathrm{P}<0.05$ and ${ }^{* *} \mathrm{P}<0.01$ indicated statistical significance, compared with controls, as analyzed by the Student's t-test.

apoptosis at this relatively low dosage. Previous evidence has suggested that the safe and tolerated therapeutic dosage range of ATST is $10-80 \mathrm{mg} /$ day (26). This dosage range is lower for ATST when administered to exhibit a protective effect against colorectal cancer. Our results suggested a combination strategy for the prevention of colorectal cancer based on the synergy between ATST and PT. Through this combination, the growth inhibition effect of ATST would be substantially increased at a relatively low dosage.

Similar to ATST, this enhancement effect is also applicable to PT. The in vivo activities of phytochemicals are usually restricted due to poor bioavailability. Although previous studies 

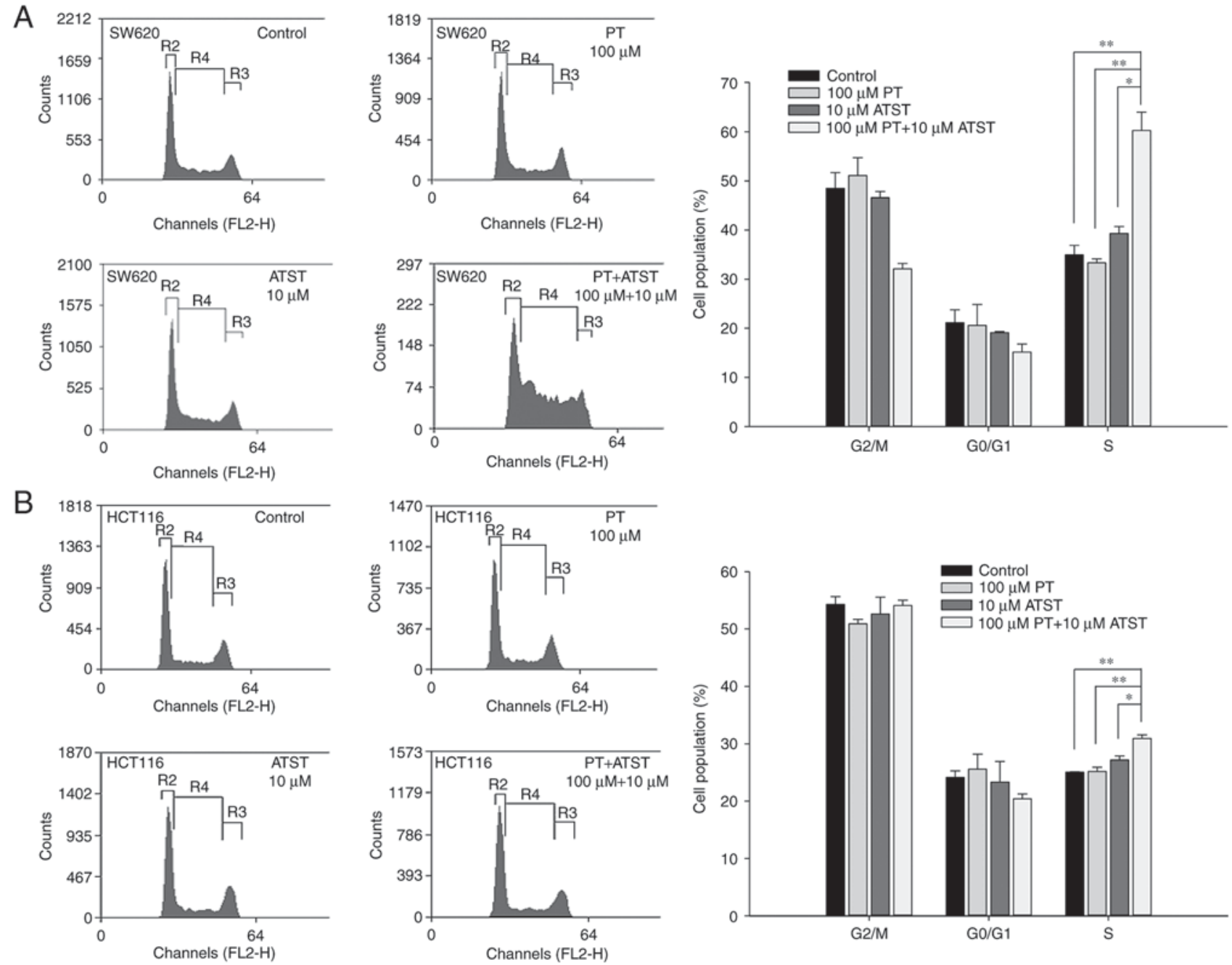

Figure 4. Effects of PT, ATST or a combination on the cell cycle in SW620 (A) and HCT116 (B) cells. Cells were treated with PT (100 $\mu$ M), ATST (10 $\mu$ M) or a combination for $48 \mathrm{~h}$, and the cell distribution was detected by flow cytometry. The quantified data of the cell population in the $\mathrm{S}$ phase are shown as the percentage compared with the total cell counts. Data are shown as the mean $\pm \mathrm{SD}(n=3) .{ }^{*} \mathrm{P}<0.05$ and ${ }^{* *} \mathrm{P}<0.01$ indicated statistical significance, compared with controls, as analyzed by the Student's t-test.

have reported the anti-proliferative effects of PT on HL-60, HT29 and HepG2 cells, the effective dosages of PT were all $>100 \mu \mathrm{M}(18,20,22)$. Concordantly, our results showed that, in both SW620 and HCT116 cells, PT could not efficiently inhibit cell growth unless the dose was higher than $100 \mu \mathrm{M}$. Although previous studies have reported that cytochalasin B could enhance the PT-induced apoptosis of HepG2 cells (21), and that PT can potentiate the anticancer activity of paclitaxel (22), no prior research has focused on synergy involving PT. The results of the present study demonstrated that the antitumor efficacy of ATST could be enhanced at a relatively low dosage through the synergistic action with PT, which suggested the potential interaction of statins with other compounds in the food matrix. This interaction affects the efficacy of statins, and may explain the controversial results obtained in prior studies regarding the associations between statin use and the risk of colon cancer-associated mortality $(27,28)$. As the dietary composition is different for each individual, this can result in varying statin efficacy. Conversely, different statins have different antitumor effects. In six colorectal cancer cell lines, including DLD1, HT29, SW620, HCT116, LoVo and colo320, simvastatin and fluvastatin showed strong growth suppressive effects. Atorvastatin demonstrated a relatively weak growth suppressive effect, whereas no growth suppressive effect was observed with pravastatin (29). This may be another reason for the paradoxical results regarding the antitumor effects of statins.

A close relationship is believed to exist between the cell cycle and apoptosis in cancer cells (30). Numerous studies have reported PT-induced apoptosis; however, few of these results involved the cell cycle, especially in colon cancer cells. Some data supported that the presence of HMG-CoA reductase inhibitors may influence the cell cycle distribution of cancer cells. Known as the typical statin family compound, ATST has been shown to induce colon cancer cell cycle arrest in the $\mathrm{G}_{0} / \mathrm{G}_{1}$ phase when combined with other compounds $(11,12)$. Therefore, we decided to determine whether treatments with PT and ATST could regulate the cell cycle distribution of SW620 and HCT116 cells. The results partly confirmed our hypothesis, in that the cell cycle was arrested, but also demonstrated that the cells were arrested at the $\mathrm{G}_{2} / \mathrm{M}$ checkpoint and accompanied by an increased cell population in the $\mathrm{S}$ phase, rather than arrested in the $G_{0} / G_{1}$ phase. Specifically, cdc2 kinase activation is the pivotal regulator mechanism 
A
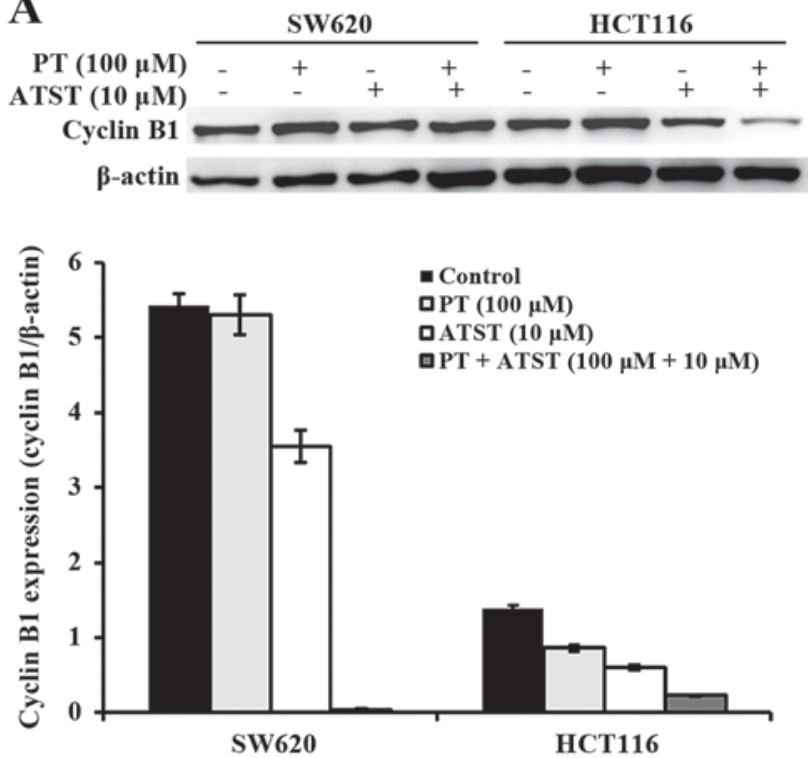

B
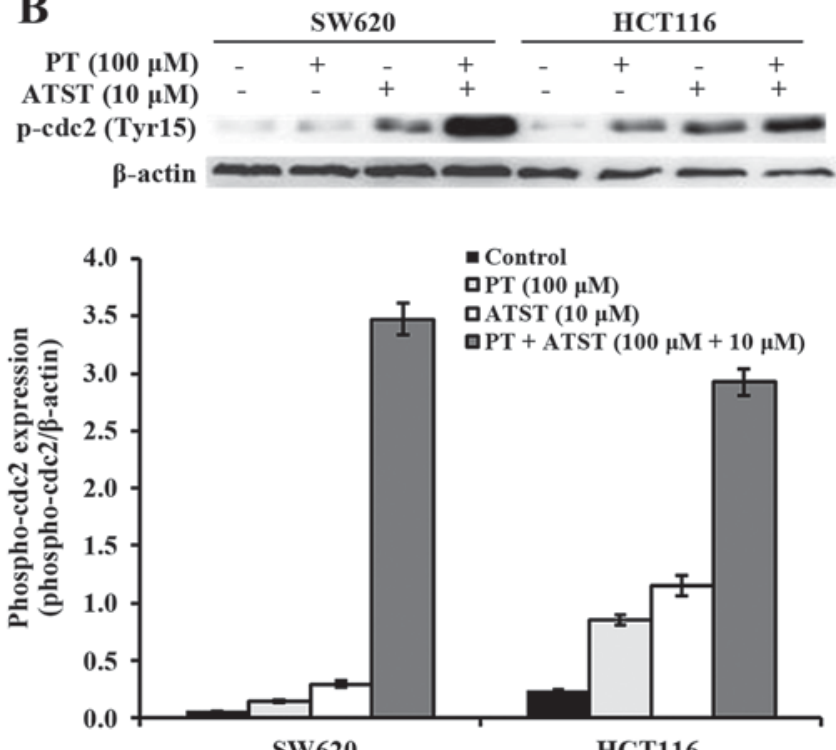

C
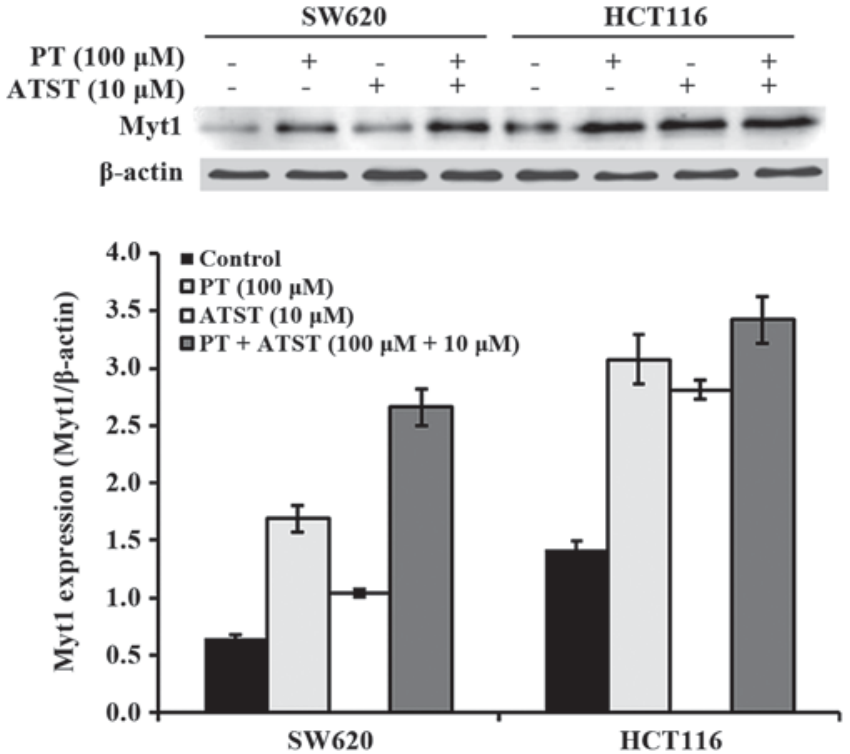

Figure 5. Effects of PT, ATST or a combination on the levels of cyclin B1 (A), p-cdc2 (B) and Myt1 (C) in SW620 and HCT116 cells. Cells were treated with PT $(100 \mu \mathrm{M})$, ATST $(10 \mu \mathrm{M})$ or a combination of the two for $48 \mathrm{~h}$, and the protein levels were analyzed by western blotting. Combined treatments suppressed the levels of cyclin B1, and increased the levels of p-cdc2 and Myt1. The quantified levels of cyclin B1, p-cdc2 and Myt1 are shown as the mean \pm SD $(n=3)$.

responsible for the $\mathrm{G}_{2} / \mathrm{M}$ checkpoint. Activation of cdc2 is controlled via two steps: One is cyclin binding; the other is the dephosphorylation of cdc2 at Tyr15, which is the core regulatory step (31).

In the present study, we observed that PT and ATST synergistically downregulated the expression of cyclin B1, which indicated that formation of the cyclin B-cdc2 complex might be inhibited. In addition, our data showed that the level of cdc2 phosphorylation at Tyr15 was markedly increased by combined treatment with PT and ATST. These results demonstrated that the cdc2 kinase was inactivated, possibly due to a failure to bind to cyclin $\mathrm{B}$ and the increased levels of p-cdc2 at Tyr15. Myt1 protein kinase is regarded as a negative modulator of cdc2, and carries out the phosphorylation of cdc2 at Tyr15 (32). The p21 gene is an inhibitor of cyclin; hyper-phosphorylation of p21 activates cdc2 kinase in the $\mathrm{G}_{2} / \mathrm{M}$ transition $(33,34)$. Previous studies have shown that ATST can increase p21 levels in A549 cells (35) and the pancreatic cancer (36). However, Buranrat et al reported opposing results, stating that ATST reduced p21 expression in KKU-100 cells and did not alter p21 expression in KKU-M214 cells (37). In terms of the synergistic effect, p21 levels were increased in HT29 and HCT116 cells following treatment with combined ATST and celecoxib (11), and with combined ATST and $\gamma$-tocotrienol (12). Therefore, the p21 gene may be the potential regulatory target underlying the $\mathrm{G}_{2} / \mathrm{M}$ phase arrest following the synergistic action of ATST and PT; more in depth future investigations are warranted.

In summary, the present study demonstrated that PT and ATST produce a powerful synergistic interaction in suppressing colon cancer cell growth. This process was accomplished via the synergistic induction of apoptosis and the arrest of the cell cycle at the $\mathrm{G}_{2} / \mathrm{M}$ checkpoint, which resulted from downregulated cdc2 activation following combined treatment. 


\section{Acknowledgements}

The present study was conducted using grants supported by the Chinese Academy of Agricultural Sciences (grant no. 2014ZL041).

\section{References}

1. Baena R and Salinas P: Diet and colorectal cancer. Maturitas 80: 258-264, 2015

2. Lippi G, Mattiuzzi C and Cervellin G: Meat consumption and cancer risk: A critical review of published meta-analyses. Crit Rev Oncol Hematol 97: 1-14, 2016.

3. Keshk WA, Zineldeen DH, Wasfy RE and El-Khadrawy OH: Fatty acid synthase/oxidized low-density lipoprotein as metabolic oncogenes linking obesity to colon cancer via NF-kappa B in Egyptians. Med Oncol 31: 192, 2014.

4. Davis-Yadley AH, Lipka S, Shen H, Devanney V, Swarup S, Barnowsky A, Silpe J, Mosdale J, Pan Q, Fridlyand S, et al: Ethnic disparities in the risk of colorectal adenomas associated with lipid levels: A retrospective multiethnic study. J Gastrointest Cancer 46: 29-35, 2015.

5. Reverter M, Rentero C, Garcia-Melero A, Hoque M, Vilà de Muga S, Alvarez-Guaita A, Conway JR, Wood P, Cairns R, Lykopoulou L, et al: Cholesterol regulates Syntaxin 6 trafficking at trans-Golgi network endosomal boundaries. Cell Rep 7: 883-897, 2014.

6. Sheng R, Kim H, Lee H, Xin Y, Chen Y, Tian W, Cui Y, Choi JC, Doh J, Han JK, et al: Cholesterol selectively activates canonical Wnt signalling over non-canonical Wnt signalling. Nat Commun 5: 4393, 2014.

7. Nielsen SF, Nordestgaard BG and Bojesen SE: Statin use and reduced cancer-related mortality. N Engl J Med 367: 1792-1802, 2012.

8. Poynter JN, Gruber SB, Higgins PD, Almog R, Bonner JD, Rennert HS, Low M, Greenson JK and Rennert G: Statins and the risk of colorectal cancer. N Engl J Med 352: 2184-2192, 2005.

9. Lytras T, Nikolopoulos G and Bonovas S: Statins and the risk of colorectal cancer: An updated systematic review and meta-analysis of 40 studies. World J Gastroenterol 20: 1858-1870, 2014.

10. Xiao $\mathrm{H}$ and Yang CS: Combination regimen with statins and NSAIDs: A promising strategy for cancer chemoprevention. Int J Cancer 123: 983-990, 2008.

11. Xiao H, Zhang Q, Lin Y, Reddy BS and Yang CS: Combination of atorvastatin and celecoxib synergistically induces cell cycle arrest and apoptosis in colon cancer cells. Int J Cancer 122: 2115-2124, 2008.

12. Yang Z, Xiao H, Jin H, Koo PT, Tsang DJ and Yang CS: Synergistic actions of atorvastatin with gamma-tocotrienol and celecoxib against human colon cancer HT29 and HCT116 cells. Int J Cancer 126: 852-863, 2010.

13. Lu G, Xiao H, You H, Lin Y, Jin H, Snagaski B and Yang CS: Synergistic inhibition of lung tumorigenesis by a combination of green tea polyphenols and atorvastatin. Clin Cancer Res 14: 4981-4988, 2008.

14. Bazzano LA, Serdula MK and Liu S: Dietary intake of fruits and vegetables and risk of cardiovascular disease. Curr Atheroscler Rep 5: 492-499, 2003.

15. Liu RH: Health benefits of fruit and vegetables are from additive and synergistic combinations of phytochemicals. Am J Clin Nutr 78 (3 Suppl): 517S-520S, 2003.

16. Boyer J and Liu RH: Apple phytochemicals and their health benefits. Nutr J 3: 5, 2004.

17. Hyson DA: A comprehensive review of apples and apple components and their relationship to human health. Adv Nutr 2: 408-420, 2011

18. Kobori M, Iwashita K, Shinmoto $H$ and Tsushida $T$ : Phloretin-induced apoptosis in B16 melanoma 4A5 cells and HL60 human leukemia cells. Biosci Biotechnol Biochem 63: 719-725, 1999.
19. Iwashita K, Kobori M, Yamaki K and Tsushida T: Flavonoids inhibit cell growth and induce apoptosis in B16 melanoma 4A5 cells. Biosci Biotechnol Biochem 64: 1813-1820, 2000.

20. Park SY, Kim EJ, Shin HK, Kwon DY, Kim MS, Surh YJ and Park JH: Induction of apoptosis in HT-29 colon cancer cells by phloretin. J Med Food 10: 581-586, 2007.

21. Wu CH, Ho YS, Tsai CY, Wang YJ, Tseng H, Wei PL, Lee CH, Liu RS and Lin SY: In vitro and in vivo study of phloretin-induced apoptosis in human liver cancer cells involving inhibition of type II glucose transporter. Int J Cancer 124: 2210-2219, 2009.

22. Yang KC, Tsai CY, Wang YJ, Wei PL, Lee CH, Chen JH, Wu CH and Ho YS: Apple polyphenol phloretin potentiates the anticancer actions of paclitaxel through induction of apoptosis in human hep G2 cells. Mol Carcinog 48: 420-431, 2009.

23. Chou TC and Talalay P: Quantitative analysis of dose-effect relationships: The combined effects of multiple drugs or enzyme inhibitors. Adv Enzyme Regul 22: 27-55, 1984.

24. Gazzerro P, Proto MC, Gangemi G, Malfitano AM, Ciaglia E, Pisanti S, Santoro A, Laezza C and Bifulco M: Pharmacological actions of statins: A critical appraisal in the management of cancer. Pharmacol Rev 64: 102-146, 2012.

25. Huang EH, Johnson LA, Eaton K, Hynes MJ, Carpentino JE and Higgins PD: Atorvastatin induces apoptosis in vitro and slows growth of tumor xenografts but not polyp formation in MIN mice. Dig Dis Sci 55: 3086-3094, 2010.

26. Athyros VG, Tziomalos K, Karagiannis A and Mikhailidis DP: Atorvastatin: Safety and tolerability. Expert Opin Drug Saf 9: 667-674, 2010.

27. Gray RT, Loughrey MB, Bankhead P, Cardwell CR, McQuaid S, O'Neill RF, Arthur K, Bingham V, McGready C, Gavin AT, et al: Statin use, candidate mevalonate pathway biomarkers and colon cancer survival in a population-based cohort study. Br J Cancer 116: 1652-1659, 2017.

28. Voorneveld PW, Reimers MS, Bastiaannet E, Jacobs RJ, van Eijk R, Zanders MMJ, Herings RMC, van Herk-Sukel MPP, Kodach LL, van Wezel T, et al: Statin use after diagnosis of colon cancer and patient survival. Gastroenterology 153: 470-479.e4, 2017.

29. Ishikawa S, Hayashi H, Kinoshita K, Abe M, Kuroki H, Tokunaga R, Tomiyasu S, Tanaka H, Sugita H, Arita T, et al: Statins inhibit tumor progression via an enhancer of zeste homolog 2-mediated epigenetic alteration in colorectal cancer. Int J Cancer 135: 2528-2536, 2014

30. Evan GI and Vousden KH: Proliferation, cell cycle and apoptosis in cancer. Nature 411: 342-348, 2001.

31. FisherD, Krasinska L, Coudreuse D and Novák B: Phosphorylation network dynamics in the control of cell cycle transitions. J Cell Sci 125: 4703-4711, 2012.

32. Chow JP and Poon RY: The CDK1 inhibitory kinase MYT1 in DNA damage checkpoint recovery. Oncogene 32: 4778-4788, 2013.

33. Zhan Q, Antinore MJ, Wang XW, Carrier F, Smith ML, Harris CC and Fornace AJ Jr: Association with Cdc2 and inhibition of $\mathrm{Cdc} 2 /$ Cyclin B1 kinase activity by the p53-regulated protein Gadd45. Oncogene 18: 2892-2900, 1999.

34. Dash BC and El-Deiry WS: Phosphorylation of p21 in G2/M promotes cyclin B-Cdc2 kinase activity. Mol Cell Biol 25: 3364-3387, 2005.

35. Lin YC, Lin JH, Chou CW, Chang YF, Yeh SH and Chen CC: Statins increase p21 through inhibition of histone deacetylase activity and release of promoter-associated HDAC1/2. Cancer Res 68: 2375-2383, 2008.

36. Mohammed A, Qian L, Janakiram NB, Lightfoot S, Steele VE and Rao CV: Atorvastatin delays progression of pancreatic lesions to carcinoma by regulating PI3/AKT signaling in p48Cre/+ LSL-KrasG12D/+ mice. Int J Cancer 131: 1951-1962, 2012.

37. Buranrat B, Senggunprai L, Prawan A and Kukongviriyapan V: Simvastatin and atorvastatin as inhibitors of proliferation and inducers of apoptosis in human cholangiocarcinoma cells. Life Sci 153: 41-49, 2016. 